\title{
Toward Interpretive Methodology of International Human Rights Education
}

\author{
Guangyu Cao, Yanying Fei \\ Faculty of Humanities and Social Sciences of Dalian University of Technology Dalian 116024, China \\ sptlt@163.com, feiyanying@126.com
}

\begin{abstract}
The purpose of this paper is to articulate the epistemological foundations of international human rights education (IHRE) from the perspective of a hermeneutical interpretive methodology. This methodology potentially alleviates the challenges that face the cross-cultural implementation of human rights education. While acknowledging the necessity of global human rights awareness, the authors maintain that local cultural conceptualization is imperative to the negotiated, local embrace of human rights. A critical, interpretive pedagogy emerges from grounding human rights education in a hermeneutic methodology.
\end{abstract}

Index Terms - international human rights education, interpretive methodology, pedagogy science

\section{A Challenge of Interpretive Methodology about IHRE}

International human rights education (hereafter IHRE) currently faces many challenges. These challenges include the issue of legitimacy, the disparity between the reality of the human condition and the conceptual ideal of human rights, the use of one conception of human rights as representative of all traditions (which, consequently, leads to a lack of recognition of diverse cultural traditions conducive to human rights education), the focus of IHRE on content knowledge, and the lack of a theoretical framework. Although it is beyond the scope of this paper to discuss these challenges in detail, it is important to explain them briefly in order to demonstrate the need for the methodological framework we propose here.

The dissemination of human rights in other cultures does not require that a country or culture build its human rights knowledge upon a Western liberal philosophy of human rights. John Rawls explained that human rights enforcement and protection does not require all regimes to be liberal. This is due to the fact that a non-liberal society will accept the same law of peoples that well-ordered liberal societies accept. In order to become a reality, human rights, and their equivalents in other cultures, must satisfy certain conditions of legitimacy. Rawls defined the law of peoples as "a legal system that satisfies certain requisite conditions of legitimacy in the eyes of its own people; and, as a consequence of this, it honors basic human rights." Satisfying the conditions of legitimacy is contingent upon the legal system's capability of honoring human rights.

A situation-specific justification satisfies the conditions of legitimacy with regard to human rights and human rights education, according to Bell, for it refers to cultural traditions that may well provide "the resources to justify and increase local commitment to values and practices that in the West are typically realized through a human rights regime." Building on specific local justification of human rights, and channeling this process toward human rights education, could overcome the issue of the legitimacy of IHRE since "the ultimate aim of human rights diplomacy is to persuade others of the value of human rights"; therefore "it is more likely that the struggle to promote human rights can be won if it is fought in ways to build on, rather than challenge, local cultural tradition." One of the central claims of this paper is that the issues of justification and legitimacy could be properly addressed if human rights educators use what we refer to as the isomorphic equivalents of human rights as a source of justification, legitimacy, and education about human rights. Isomorphic equivalents of human rights are referred to in the literature as "structural equivalents of human rights". These notions are also referred to as "functional equivalents of human rights." We use the term "isomorphic" because it captures the essence of the meaning, function, and structure of moral concern. In different cultures, is structural-equivalents of human rights have the structure and function of human rights: they morally regulate human relations within and between cultures. These equivalents are codified within particular legal and ethical cultural systems.

In addition, there is a divide between the current form of human rights education and the culture within which it is practiced. This issue has challenged the successful implementation of human rights education since "every society struggles to better embody human rights principles." The embodiment of human rights principles is contingent on engaging culture and community, not only as a partner and supporter of the educational process, but also as an informer and director of education.

The efforts of human rights education programs to draw on the agent's reasons, motives, and intentions have fallen short, considering that IHRE has mainly been informed by the Western liberal tradition of human rights. This has, in turn, generated significant obstacles to the implementation of IHRE. One issue in particular is the abstractness of the educational process given that its pedagogy and curriculum are drawn from the Western tradition. IHRE has been informed by the liberal conceptualization of human rights. In this conceptualization, international treaties and conventions represent the main source of pedagogy and curriculum for educators and learners in the global context. Although we believe that these treaties and conventions set important standards by which to achieve and to evaluate human rights, we think that drawing upon them 
as the most important source of curriculum and pedagogy misuses them.

These treaties and instruments connote a picture of what ought to be realized with regard to human rights. Consequently, the conceptualization of rights is perceived as an obligation to realize an idealized, unassailable conception of the good life. This conceptualization makes human rights a set of final truths that all countries and cultures are to uphold. Other contexts, and contents, that are related to human rights are not considered as contributing to what ought to be good. Constitutive texts that provide the experiential meaning of human rights - exemplified in Buddhism, Confucianism, Hinduism, Taoism, African traditions, Islam, and the like are rendered irrelevant.

If human rights are to be realized and recognized globally, through human rights education, it is important to consider inputs in relation to the human rights corpus and conceptualization from diverse cultural backgrounds. The plurality of human rights inputs could initiate a sense of ownership of human rights among cultural groups. In addition to developing this sense of ownership, a dialogue concerning the meaning of human rights could contribute to the beneficial modification or enlargement of the human rights ethos and corpus. This possibility constitutes another reason for considering plural conceptualizations with regard to human rights education. Therefore, it is important for any human rights education to start with the recommendation of the People's Decade of Human Rights Education, which specifies that the aspiration of human rights education is to engage individuals and communities dialectically. This aspiration requires more than knowledge of the content and mechanisms of international human rights instruments, which is the focus of much traditional human rights teaching. To fulfill this aspiration, practitioners in the field must latch on to, and mobilize, culturally legitimate signs, forms, artifacts, and languages that make its message more resonant, more inviting, and more palatable among the target population. The authenticity of human rights education is potentially increased through the process of cultural legitimization.

There is a need for an authentic cosmopolitan consensus on universal human rights. Such a consensus cannot be formed by a monologue in which the Western world view is uncritically proselytized without it benefiting from other views on human rights and human rights education. It is only through a genuine dialogue that is based on equality and respect, between and among peoples, that an authentic consensus will be fostered - one that is inclusive. For this reason we feel it is important to introduce a dialogical, hermeneutical approach to human rights and human rights education, one with the potential to nurture an ethics of respect and recognition. Under these circumstances the current paradigm is not a suitable philosophical posture for any human rights project that hopes to gain widespread legitimacy among historically skeptical Third World mass populations. Rather, the philosophical posture of any human rights project should be established on the cultural recognition, and thereby the equal dignity, of all participants in a human rights education. For this reason, it is important to develop a methodological framework that envisions a post-universalist international human rights education.

\section{A Note on Moral Universalism and Relativism}

It is important to note that the approach articulated in this paper is an attempt at a conceptualization of human rights midway between universalism and relativism. It is an approach that seeks a fusion of horizons, a cross-cultural consensus on human rights; however, this consensus is not based in moral realism or in transcendental idealism, but it is conceptualized and affirmed from within a plurality of cultures. It rests upon the plausibility of our capacity to transcend but also to include particularistic cultural traditions in order to achieve an impartial, nonrelativistic perspective.

The idea of human rights has its origins in the natural law tradition in moral and political philosophy. This tradition maintains that as a matter of the dictates of reason, reason that is universally shared among human beings, individuals have a legitimate and justifiable moral claim to be treated in certain ways and to be provided certain goods. In other words, by the dictates of reason human beings possess natural rights. This position holds that there is an independent and universal order of value that can be comprehended by human reason.

From another perspective, Immanuel Kant framed rights not in terms of an independent moral order, but in terms of moral autonomy and practical reason - his idea was that human beings give themselves moral rights. In Kantian constructivism, ethical principles, including rights, are expressions of the nature of practical reason, of our capacity for a sense of justice. Principles originate in the person conceived as morally autonomous. Ethical principles are the moral imperatives given to one's self as a morally autonomous, reasonable and rational person.

From the perspective of both moral realism and transcendental idealism, human rights are either discovered by, or autonomously constructed from within, universal practical reason. In the historical development of the idea of human rights, the foundation of rights in these two traditions has been contested, with critics maintaining that rights derive not from a universal truth but from a culturally positioned understanding. Furthermore, critics argue that the portrayal of rights as natural and universal constitutes an unjust cultural imposition. In other words, a cross-cultural conception of human rights cannot be grounded in claims of universal human reason but must be constructed and interpreted from within a plurality of cultural, religious, and philosophical doctrines. Such interpretation necessarily requires shared understandings that rest on social norms inherent in the background culture of the society.

One prominent example of this turn in theory is the interpretive perspective offered by Michael Walzer. Walzer maintains that moral and political philosophy proceeds intellectually by the application of an interpretive method. Morality is neither discovered in the fabric of reality, nor is morality invented, that is constructed through purely 
procedural processes that model the nature of practical reason itself. Walzer argues that we do not have to discover or invent the moral world; it already exists and we are situated within it. We always perceive and understand from a position, a point of view. Our own communities and cultures are our ultimate source of morality; we do not need to discover or invent it, but instead we need to interpret it. There is no other starting point for moral speculation - we start from where we are, reflecting on existing moral and political beliefs, which entails argument and deliberation about the meaning of the good and the right. It is the interpretation itself that contains the content of moral judgment.

This turn in approaching the idea of human rights is also consistent with Rawls's idea of political constructivism, an idea he developed in response to the inherent instability of a conception of justice grounded in comprehensive moral doctrines such as Kantian constructivism or natural law theory. In Political Liberalism, Rawls rejected Kantian constructivism on the grounds that it is a comprehensive moral doctrine, and being a comprehensive doctrine, it is incompatible with the social fact of pluralism. According to Rawls, political liberalism must, of course, reject Kant's constitutive autonomy. In place of Kantian constructivism, he proposed a political constructivism as a mode of justification of principles of political justice grounded in the shared fundamental ideas of the political culture.

Political liberalism suggests that a political conception of justice, including a conception of human rights, is not discovered or invented as such. The formulation of a political ethic, including its conception of human rights, is primarily an interpretive process that leads to an overlapping consensus among a plurality of comprehensive doctrines. As Rawls described that we turn to the fundamental ideas we seem to share through the public political culture. From these ideas we try to work out a political conception of justice congruent with our considered convictions on due reflection. In other words, the political conception of justice is derived from a shared understanding of the values and principles of citizens within a political culture based upon reciprocity and mutual agreement.

From this perspective, the conceptualization and affirmation of human rights is contingent on dialogue within and across cultures. A genuine dialogue that is based on equality and respect is necessary in order to foster an appropriate paradigm, one that is inclusive and conducive to human rights education. For this reason, we feel it is of cardinal importance to introduce a methodology that potentially could nurture an ethics of respect and recognition: the application, following Rawls, of the principle of toleration to the philosophy of human rights education itself.

This approach constitutes a third conceptualization of human rights that seeks to reconcile the debate between universalists and cultural relativists. While accepting the basic tenets of antifoundationalism, particularism, perspectivalism, and historicism, this middle way rejects the most radical of the cultural relativists, which holds that no ideals stretch across cultures, that normative judgment is deeply flawed and untenable, and that all that remains is power. This third way holds to the normative power of justice and human rights while being grounded in cultural interpretation.

However, if the understood meaning and the ethical affirmation of human rights are contingent upon cultural interpretation, then a methodological approach to interpretation is needed. Such an approach is central to normative interpretation, upon which the plausibility of an impartial perspective rests. Furthermore, the interpretive methodology is also required as a framework for a pedagogical approach to human rights education. The specification of this methodology is our central purpose in this paper. We turn here to an account of a hermeneutical methodology as a potential method of interpretation as well as a pedagogical framework.

\section{A Critical and Interpretive Pedagogy for IHRE}

The hermeneutical approach aids human rights education in enlarging the scope of interpretive inquiry. Consequently, the epistemology empowers cultures to adapt to change. In this approach the central considerations are how learners construct human rights understanding and how learners adapt to the cultural system on a relational level, since human rights education is a major embodiment of a culture's way of life, not just a preparation for it.

Human rights education has to be consistent with the culture's way of life. Therefore, the isomorphic equivalents of human rights and the hermeneutical epistemology constitute a critical, interpretive pedagogy that may have significant value for IHRE. Here, we provide a brief summary of hermeneutics as a pedagogy of critical, interpretive inquiry.

First, a hermeneutical approach to IHRE focuses on the cultural, social, political, and historical nature of human rights education. In this context hermeneutics maintains that meaning making cannot be experienced independently from the social context. Interpretation becomes a central component of moral reasoning, moral action, and imagination in this approach. Thus, the approach connects the object of inquiry to the many contexts in which it is embedded. It also embodies the meaning of human experience as related to IHRE.

Second, our approach to IHRE is emancipatory since it offers learners the cultural tools needed to understand the concept of human rights. Therefore, the approach provides learners with human rights praxis, thus enabling them to transform their understanding by contextualizing human rights through legitimate local tools and signs of rights. In this interpretive context, critical pedagogy is connected with praxis-based concepts of social change that are easily addressed and transformed.

Third, hermeneutics draws strength from the multiple perspectives of the fusion of horizons. Including multiple perspectives on a certain subject is perceived as a strength of any educational pedagogy. Learning occurs as a learner juxtaposes divergent ideas and ways of understanding human rights concepts. Human rights learners can gain new understandings of the cultures of marginalized groups since IHRE includes voices and perspectives that have been 
traditionally excluded.

Fourth, IHRE that is grounded in hermeneutics is dedicated to challenging comfortable assumptions about politics, culture, psychology, human potential, and the moral domain. The approach entails taking a critical stance toward human rights as they are conceptualized locally, and it motivates such a stance toward other conceptualizations of human rights. The approach is motivated by a strong ethical concern for the respect and the engagement of other communities. Thus, any global engagement of human rights is achieved by close personal, local, cultural, and social understanding of the concept of rights.

Fifth, using one conceptualization of IHRE as representative of all is partial and incomplete; instead, we seek a critical pedagogy based on hermeneutics to provide a complex approach to understanding the relationship between the self and the others as evident in human rights conceptualizations. In this manner, the pedagogy that emerges from the hermeneutical approach is a plea for individual and social self-realization and self-development that is based on an accountable autonomy and respect for diverse traditions around the globe. The pedagogy is committed to understanding the social preconditions for an emancipatory project.

\section{Concluding Remarks}

A interpretive framework for human rights education is reflective of culture. The approach focuses on seeking a cross- cultural normative understanding of human rights. It engages cultures and learners in a dialogical process with regard to the diverse cultural and social representations of human rights. Taking a hermeneutical approach contributes to the legitimization, realization, and preservation of a culturally sensitive understanding of human rights and human rights education. Further, such an approach recognizes the possibility of achieving an impartial, nonrelativistic normative perspective that is affirmed from within and across diverse cultures, and thereby yields a post-universalist conception of international human rights education.

\section{References}

[1] John Rawls, The Politics of Human Rights, New York: Verso, 1999.

[2] John Rawls, Political Liberalism, New York: Columbia University Press, 1993.

[3] Immanuel Kant, Groundwork of the Metaphysics of Morals, trans. H. J. Paton, New York: Harper Torchbooks, 1964.

[4] Michael Walzer, Spheres of Justice: A Defense of Pluralism and Equality, New York: Basic Books, 1983.

[5] Michael Walzer, Interpretation and Social Criticism, Cambridge, Massachusetts: Harvard University Press, 1987.

[6] Alison Dundes Renteln, International Human Rights: Universalism Versus Relativism, Newbury Park, California: Sage, 1990.

[7] Jack Donnelly, Universal Human Rights in Theory and Practice, New York: Cornell University Press, 1989.

[8] Ronald Dworkin, Taking Human Rights Seriously, Cambridge, Massachusetts: Harvard University Press, 1977 